\title{
Estimating the Off-farm Labor Supply in Canada
}

\author{
Wayne Howard ${ }^{1}$ and Michael Swidinsky ${ }^{2}$ \\ ${ }^{1}$ Associate professor, Agribusiness Department, \\ California Polytechnic State University, San Luis Obispo, California; \\ formerly associate professor, Department of Agricultural Economics \\ and Business University of Guelph, Guelph, Ontario. \\ 2 Policy analyst, Agriculture and Agri-Food Canada.
}

\begin{abstract}
Off-farm labor supply in Canada is modeled using separate off-farm labor participation and off-farm labor supply equations, which allows variables to affect participation and labor supply differently. The data used in this study are from Statistics Canada's Agriculture-Population Linkage Database, which links the Population Census for 1986 to a 20\% sample from the Census of Agriculture. Results indicate that age, education and wages have large, significant and opposite effects on participation and supply, and that government efforts to stabilize and supplement farm incomes through rural employment programs may have less effect on labor allocation decisions than do the underlying demographic factors and regional and farm characteristics.
\end{abstract}

Nous modélisons ici les disponibilités d'emploi extérieur (hors-ferme) pour les agriculteurs, utilisant des équations distinctes pour la participation aux emplois extérieurs et pour l'offre des emplois extérieurs, ce qui permet de laisser les variables influer différemment sur les deux éléments. Les données utilisées proviennent de la base de données de Statistique Canada sur le couplage agriculture-population, laquelle relie le recensement de la population de 1986 à un échantillon de $20 \%$ prélevé sur le recensement de l'agriculture. Les résultats font voir que l'âge, le niveau de scolarisation et les salaires ont de grands effets, significatifs mais opposés, sur l'utilisation et sur les disponibilités d'emplois extérieurs et que les initiatives de l'État pour stabiliser et compléter le revenu agricole au moyen de programmes d'emploi rural auraient moins d'effets sur les décisions d'attribution des emplois que les facteurs sous-jacents relevant de la démographie et des caractéristiques particulières de chaque région et exploitation.

\section{INTRODUCTION}

Determining the factors associated with whether a farmer works off-farm or not, and for how many hours, has implications for policies and programs directed toward rural economies and the well-being of farm families. Farmers' responsiveness to local market conditions, and how that responsiveness changes as the underlying demographic factors (e.g., age, education, family structure) change, will affect the design and effectiveness of government programs. For example, a program designed to increase and/or stabilize farm family incomes through rural job creation may not be effective if the offered wages are below most farmers' reservation wage or if the reservation wage may change as age and education levels change.

Previous off-farm labor supply studies have limited applications in Canada. Perhaps the most important factor is that the great majority of the studies were in the U.S. (e.g., Gould and Saupe 1989; Huffman and Lange 1989; Lass and Gempesaw 1992; Sumner 1982). Given common culture and technology, 
it is not heroic to assume that Canadian and American farmers have similar behaviors. Nevertheless, Canada and the U.S. may have enough differences to question the assumption that off-farm labor supply is the same in both countries. Previous studies of off-farm labor supply in Canada are dated and/or are a simple reporting of cross-tabulations of characteristics of farmers (Bollman 1973) or have estimated off-farm labor supply for a single province (Furtan et al 1985). Moreover, previous studies may have had biased results due to not adjusting for censored data; i.e., both off-farm labor participants and nonparticipants were included in a single-equation model (Furtan et al 1985). This approach restricts the variables that affect the decision to participate in the off-farm labor market and labor supply to the same sign. However, factors that affect the likelihood of working off-farm may not have the same effect on the amount of time spent working off-farm.

This study estimates off-farm labor supply in Canada. Sample selection bias due to including both off-farm labor participants and nonparticipants in the sample is tested for and appropriate adjustments made. A two-stage model of the decision to work offfarm and then the number of hours worked off-farm yields unbiased results of off-farm labor in Canada by region and commodity type. The data used in this study link the 1986 Population Census to the Census of Agriculture. This paper is the first time offfarm labor supply for all of Canada has been published using this unique data set.

\section{THE MODEL}

To establish an off-farm labor supply function, consider a farm operator whose utility is assumed to be a function of goods, $G$, purchased for $P_{G}$, and leisure, $L$ :

$$
U=U(G, L) \text {, where } U_{G}>0, U_{L}>0
$$

Utility is maximized subject to time, wages, farm profits and other income constraints. Total time available, $T$, is allocated between farm work, $F W$, off-farm work, $O F W$, and leisure:

$$
T=F W+O F W+L
$$

Income is generated through wages, $W$, farm profits and other income, $V$. Wages depend on human capital characteristics, $H$, and labor market conditions, $M$ :

$$
W=W(H, M)
$$

Farm profits are determined by farm output price, $P_{F}$, and farm output, $Q$, which is a concave production function:

$$
Q=f(F W, X ; H, E, F)
$$

Output depends on the amount of labor time spent on the farm and other inputs, $X$, purchased at price $P_{X}$, given human capital characteristics, $H$, farm characteristics, $E$, and family characteristics, $F$.

Following Huffman (1980, 1991), our farmer behaves as if she maximizes:

$$
\begin{gathered}
H=\left(G, L, F W, O F W, \lambda, \gamma ; P_{G}, P_{F}, P_{X},\right. \\
H, E, F, V, T) \\
=U(G, L)+\lambda\left[P_{F} f(.)-P_{X} X+\right. \\
\left.W(.) O F W+V-P_{G} G\right] \\
\gamma[T-F W-O F W-L]
\end{gathered}
$$

Taking the first-order conditions of Eq. 5, assuming an interior solution and substituting, one can obtain:

$$
\begin{gathered}
O F W^{*}=T-F W^{*}-L^{*} \\
=O F W\left(W, P_{F}, P_{G}, P_{X}, T, H, E, F, V\right)
\end{gathered}
$$

where $*$ indicates an optimum obtained from the first-order conditions.

Given little variation in prices and time available, off-farm labor supply can be modeled as a function of market wages, human capital, farm and family characteristics and other income ${ }^{1}$ :

$$
O F W^{*}=O F W(W, H, E, F, V)
$$




\section{ECONOMETRIC PROCEDURES}

Not all farmers participate in off-farm work. To estimate off-farm labor supply, it is necessary to have wage rates both for farmers who work off-farm and for those who do not work off-farm. The shadow wage rates for farmers not working off-farm can be predicted from a wage equation estimated from information obtained from those operators who work off-farm. However, operators who work off-farm may be systematically different in terms of unobservable characteristics from those who do not work off-farm. Prediction of the wage rate based on estimates obtained from a censored sample of operators who work off-farm may be subject to selection bias. As a result, ordinary least squares estimates may be biased and inconsistent.

Given that estimates of off-farm labor supply not corrected for censored data will be biased and inconsistent, a three-step procedure is used to correct for the censored nature of the data (Heckman 1974, 1976, 1979). First, an off-farm participation equation is estimated in order to obtain an inverse Mill's ratio and an earnings function for labor market participants. Second, the earnings function equation is used to predict the opportunity or shadow wages for farmers who do not work off-farm. Third, the predicted wage rate is included for non-off-farm workers in the estimation of the off-farm labor supply. The econometric procedures are as follows.

Off-farm labor participation can be modeled as:

$$
z=a x+u
$$

where $z=1$ if the farmer works off-farm, $z=$ 0 otherwise. Each farm operator has a reservation wage:

$$
Y_{r}=h(H, E, F, V)
$$

and faces a market wage $Y_{m}$. If $Y_{m}>Y_{r}$, then $z=1$. Otherwise, $z=0 . Y_{r}$ is not observable. However, actual wages received, $y$, and the factors in Eq. 7 are observable. Wages received can be modeled as:

$$
y=b x+e
$$

where $x$ is a vector of the variables in Eq. 8 . $z=1$ if wages $y>0$, and $z=0$ if $y=0$. Given $e, u \sim n\left(0, \sigma_{i}\right)$ with correlation $\rho r$, Eq. $8^{*}$ is estimated as:

$$
E[y \mid z=1]=b x+\rho \sigma_{e} \lambda\left(\alpha_{u}\right)+v
$$

where $\lambda\left(\alpha_{u}\right)=\phi(a x) / \Phi(a x)$, and $\phi$ and $\Phi$ are the standard normal pdf and CDF, respectively, for off-farm labor participants.

Wages are then estimated including $\lambda$ as an explanatory variable. If $\lambda$ is significant, then the censored sample (i.e., only off-farm labor participants) is biased and Heckman's procedure must be used with $\lambda$ correcting for the bias. This predicted wage rate is used as an explanatory variable in the off-farm labor supply equation.

Off-farm labor supply is estimated with the aggregate sample using a Tobit procedure. A Tobit procedure is appropriate as it combines Probit and truncated regression to account for off-farm labor participation and off-farm labor supply (Killingsworth 1983). However, the Tobit model restricts the variables that explain participation and the amount of off-farm labor supplied to the same sign (Lin and Schmidt 1984). The significance of this restriction can be tested by estimating the three models and computing:

$$
L R=-2\left[\ln L_{T}-\left(\ln L_{P}+\ln L_{T R}\right)\right.
$$

where $L_{T}, L_{P}$ and $L_{T R}$ are the likelihoods for the Tobit, Probit and truncated regression models, respectively. If the restrictions imposed by the Tobit model are not valid, modeling off-farm participation and labor supply separately using Probit and truncated regression procedures is preferable.

\section{DATA}

The data used in this study are from Statistics Canada's Agriculture-Population Linkage 
Database of census-farm operators, which links the Population Census for 1986 to a $20 \%$ sample from the Census of Agriculture. A census-farm was defined as an agricultural holding with sales of agricultural products of at least $\$ 250$ in the previous 12 months. $^{2}$ The aggregate sample had 53,143 observations, of which 29,892 reported off-farm earnings. Summary statistics for off-farm labor participants and nonparticipants characteristics are reported in Table 1.

Twenty-nine of the 36 variables listed in Table 1 are significantly different between off-farm labor participants and nonparticipants. Participants are usually younger, have more formal education and have fewer years of experience farming. Nonparticipants report gross farm sales almost three times as large as that of participants. Intuitively, one would expect farm type to be significant in explaining whether a farmer participates in off-farm work. This expectation clearly holds for dairy and beef cattle operations i.e., dairy farmers are much less likely to work off-farm than are beef farmers - but differences are much smaller, though still significant, for other types of operations. Family characteristics appear to be important. Nonparticipants are more likely to have a son and/or spouse in agricultural occupations. Having a spouse in a nonagricultural occupation is associated with increased participation. Likewise, nonparticipants reported lower spousal income, but higher farm income, family income and government support. Labor market conditions as proxied by population density and the local male unemployment rate have mixed affects. Participants appear to live in more densely populated areas, but the difference is not significant, while the male unemployment rate in their local area is significantly higher. Lastly, off-farm participation is significantly different across Canada. Offfarm labor participation is more likely in British Columbia, Ontario and Atlantic Canada, and less likely in the prairies and Quebec. Further details are available in Swidinsky et al (1998).

\section{RESULTS}

\section{Probit Equation}

The Probit equation of off-farm labor participation used to derive the inverse Mill's ratio, $\lambda$ (i.e., the ratio of the standard normal pdf and CDF for off-farm labor participants), has a pseudo $R^{2}$ of 0.23 and correctly predicts $75 \%$ of the 53,143 observations. Twenty-seven of its 32 variables are significant. However, as the purpose of the Probit equation is to derive the inverse Mill's ratio, the parameter estimates are not reported and no inferences are made about the estimates.

\section{Wage Equation}

Results for the off-farm wage equation, adjusted for selectively bias, are reported in Table 2. Only 17,947 of the 23,251 operators who reported off-farm work also reported wage earnings. Hence, off-farm wages are estimated using the smaller sample. The inverse Mill's ratio is positive and significant at the 5\% level, indicating that farmers who work off-farm have unmeasured characteristics that command higher wages than nonparticipating farmers. Not adjusting for these unmeasured characteristics can cause selectivity bias. Gunter and McNamara (1990) report similar results.

Results for the wage equation are mostly as expected. Wages increase with level of education, and increase at a decreasing rate with experience. Wages also increase with the local population density and the local male unemployment rate. Somewhat surprising is that region does not significantly affect wages. It is possible that regional wage differences are fully captured by population density and unemployment rate.

\section{Tobit Equation}

The single-equation Tobit model is tested against the alternate specification as outlined in Eq. 10. The resulting chi-square of 13,461 far exceeds the critical value of 49.52 . Hence, the single-equation Tobit model is rejected in favor of separate Probit and truncated regression models. 
Table 1. Summary statistics of off-farm labor participants and nonparticipants, Canada, 1986

\begin{tabular}{lccc}
\hline Variable & Nonparticipant & Participant & Z-test \\
\hline Human capital characteristics $(\boldsymbol{H}):$ & & & \\
Age (years) & 47.17 & 42.51 & $-46.67^{*}$ \\
& $(11.58)$ & $(10.89)$ & $42.91^{*}$ \\
Education (years) & 10.2 & $(3.4$ & \\
& $(2.98)$ & & \\
Farm experience (yes = 1): & & & \\
Started farming before & 0.44 & 0.20 & $-59.24^{*}$ \\
1966 & $(0.50)$ & $(0.40)$ & $-14.40^{*}$ \\
& 0.10 & 0.07 & 1.92 \\
$1966-71$ & $(0.30)$ & $(0.25)$ & $26.34^{*}$ \\
$1971-76$ & 0.15 & 0.16 & \\
& $(0.36)$ & $(0.37)$ & $48.75^{*}$ \\
$1976-81$ & 0.11 & 0.20 & \\
$1981-86$ & $(0.32)$ & $(0.40)$ & 0.39 \\
\end{tabular}

Farm characteristics:

Gross farm sales (\$)

$\begin{array}{cc}100,281 & 34,492 \\ (243,499) & (94,002)\end{array}$

$-95.95 *$

Farm type (yes = 1):

Dairy

0.18

$(0.39)$

Cattle

Hogs

Poultry and eggs

Wheat

Other field crops

Fruit and vegetables

Other farm types

Type of ownership (yes = 1):

Sole proprietorship

Partnership

Corporation
0.20

$(0.40)$

0.05

$(0.23)$

0.02

(0.14)

0.17

(0.37)

0.24

$(0.42)$

0.04

(0.18)

0.11

(0.31)

0.80

$(0.41)$

0.13

$(0.34)$

0.08

(0.27)
$(94,002)$

0.04

$-50.38^{*}$

(0.20)

0.27

(0.45)

0.04

(0.18)

0.02

(0.15)

0.15

(0.36)

0.25

(0.43)

0.05

(0.22)

0.18

(0.38)

0.85

(0.36)

0.12

(0.32)

0.03

(0.18)
$20.38 *$

$-10.21^{*}$

$2.99 *$

$-5.81 *$

4.10*

$8.55^{*}$

$23.57 *$

$17.63 *$

$-5.71$

$-21.14 *$ 
Table 1 continued from page 5

Family characteristics $(\boldsymbol{F})($ yes $=1)$ :

Son in agricultural occupation

0.14

$(0.35)$

0.08

$-24.30^{*}$

No spouse

0.18

$(0.39)$

0.14

0.33

$(0.47)$

0.25

$(0.43)$

0.14

$(0.35)$

Spouse in agricultural occupation

0.17

$-13.39 *$

Spouse in nonagricultural occupation

0.24

Other spouse

$(0.53)$

(0.38)

0.43

(0.49)

0.27

(0.44)

Other income $(V)$ :

Spouse's earned income (\$)

3,992

$(8,130)$

6,012

$32.12 *$

Other family income (\$)

3,102

$(11,231)$

11,234

$(24,740)$

Net farm income (\$)

19,814

Family and farm income (\$)

$(29,097)$

Government farm support (\$)

21,855

$(43,979)$

$(10,111)$

2,187

$(26,249)$

2,168

$(15,323)$

13,310

$(35,072)$

7,753

$42.87 *$

$7.62 *$

$(26,088)$

$-15.23$

$-73.01 *$

$-41.76^{*}$

$-86.37$

Labor market conditions $(M)$ :

Population density (persons $/ \mathrm{km}^{2}$ )

33.60

(98.14)

35.85

$-0.44$

9.60

(4.46)

(92.84)

10.13

(4.57)

$14.76^{*}$

Region (yes = 1):

British Columbia

0.06

$(0.23)$

Prairies

0.53

$(0.50)$

Ontario

0.22

(0.41)

Quebec

0.17

(0.37)

Atlantic

0.03

(0.18)

0.09

$(0.29)$

0.50

(0.50)

0.26

(0.44)

0.11

(0.31)

0.04

(0.20)

$16.90 *$

$-7.62 *$

$11.47 *$

$-18.83$

$6.39 *$

Observations

29,892

23,251

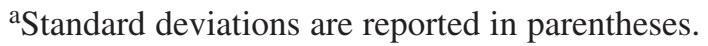

*Significantly different at the 5\% level.

Source: Statistics Canada, Census of Agriculture Match, unpublished data. 
Table 2. An off-farm wage model for labor market participants in Canada, 1986

\begin{tabular}{lcr}
\hline Variable & Parameter estimate & $t$-statistic \\
\hline Intercept & 3.416 & 65.02 \\
Education & $0.53^{*}$ & 21.93 \\
Experience & $0.035^{*}$ & 13.98 \\
Experience $^{2}$ & $-0.0005^{*}$ & -10.81 \\
Population density & $0.0004^{*}$ & 5.44 \\
Male unemployment rate & $0.011^{*}$ & 4.80 \\
British Columbia & -0.043 & -1.35 \\
West & -0.017 & -0.97 \\
Ontario (omitted) & & -0.05 \\
Quebec & -0.001 & -6.245 \\
Atlantic & -0.254 & 2.14 \\
$\lambda$ & $0.050^{*}$ & \\
Model statistics: & & \\
Observations & 17,947 & \\
$R^{2}$ & 0.43 & \\
\hline
\end{tabular}

*Significant at 5\% level.

\section{Probit and Truncated Regression Equations}

Parameter estimates and marginal probabilities for the Probit model of off-farm labor participation and the parameter estimates and elasticities at the means for off-farm labor supply for the truncated regression model are reported in Table 3. Wages are adjusted for selection bias in both models. The Probit equation correctly predicts $95 \%$ of the observations and has a pseudo $R^{2}$ of 0.50 . The truncated regression equation has a log likelihood of $-137,083$. Twenty-nine of 34 variables are significant (at the 5\% level) in the Probit equation and 18 of 34 in the truncated regression equation. Fourteen of the variables have different signs in the two models.

Human capital, $H$, as proxied by age, education, experience and wages is significant in explaining both labor participation and labor supply. As age increases, the probability of working off-farm decreases at an increasing rate, but the amount of time worked off-farm increases at a decreasing rate with age. Education also has mixed signs. An increase in education has the greatest negative marginal affect of all the variables on the probability of working off-farm, but for those farmers who do work off-farm, education increases the number of hours worked off-farm. The more experience a farmer has, as indicated by when the farmer first entered into farming, appears to decrease both the probability of labor participation and labor supply. However, a farmer with five to ten years' experience is more likely to work off-farm than farmers with either less or more experience, while labor supply more consistently decreases with years of experience.

Wages are significant in both equations, but positive for labor participation and negative for labor supply. This backward-bending labor supply curve is consistent with theory and is discussed later. Wages are highly significant in both equations and the marginal probability of wages in labor participation is the fourth highest and the elasticity of wages is relatively high in labor supply.

Farm characteristics, E, are significant in both equations. Size of operation as indicated by gross farm sales is negative and significant in both models, as expected. Type of farm is significant in off-farm participation for seven of the eight farm types modeled, but only two farm types are significant in 
Table 3. Probit model of off-farm labor participation and truncated regression model of off-farm labor supply in Canada, $1986^{\mathrm{a}}$

\begin{tabular}{|c|c|c|c|c|}
\hline \multirow[b]{2}{*}{ Variable } & \multicolumn{2}{|c|}{$\begin{array}{c}\text { Probit model of } \\
\text { off-farm labor participation }\end{array}$} & \multicolumn{2}{|c|}{$\begin{array}{l}\text { Truncated regression model } \\
\text { of off-farm labor supply }\end{array}$} \\
\hline & Parameter & Marginal probability & Parameter & Elasticity \\
\hline Intercept & $\begin{array}{l}-88.83^{*} \\
(-117.1)\end{array}$ & -32.20 & $\begin{array}{l}304.9 \\
\quad(4.41)\end{array}$ & \\
\hline
\end{tabular}

\section{Human capital $(\boldsymbol{H})$ :}

Age

Age $^{2}$

$-1.99$

$(-112.14)$

$0.02 *$

$-0.72$

$10.76^{*}$

2.625

(108.69)

Education

$$
-2.529 *
$$

0.007

(6.73)

$-0.117$

$-1.30$

$(-7.309)$

$-0.917$

$10.116^{*}$

(4.856)

\section{Farm experience:}

Entry before 1966

$$
\begin{gathered}
0.041 \\
(1.292) \\
-0.131^{*} \\
(-3.128)
\end{gathered}
$$

Entry 1966-1971

Entry 1971-1976 (omitted)

Entry 1976-1981

0.403*

(11.739)

Entry 1981-1986

$0.263^{*}$

(8.288)

Wage

$36.900^{*}$

(122.809)

0.015

$-21.515^{*}$

$-0.024$

$-0.047$

$(-6.832)$

$-3.069$

$(-0.764)$

0.146

$16.582 *$

(5.750)

0.095

$16.581^{*}$

(6.102)

0.375

$-52.065^{*}$

$(-01.973)$

Farm $(\boldsymbol{E})$ :

Gross farm sales

Type:

Dairy

$-1.389 *$

$-0.503$

$-52.824$

$-0.012$

Cattle

$(-31.411)$

$-0.137 *$

$-0.050$

(-9.236)

0.204

(0.078)

Hogs

$-0.800^{*}$

$-0.290^{\circ}$

$-4.567$

0.019

0.036

$-0.299$

Poultry

$(-15.543)$

$-0.174 *$

$-0.063$

$(-0.888)$

8.485

(1.471)

$(-2.361)$

Wheat

0.053

(1.653)

0.019

$14.007 *$

(4.697)

Crops (omitted)

Fruits and vegetables

$-0.409 *$

$(-7.824)$

$-0.148$

$-4.259$

Other

$-0.659^{*}$

$-0.239$

$(-0.984)$

$-12.115^{*}$

$-0.001$

$-0.013$

0.0003
-0.0009
0.001
0.012
-0.001
-0.013


Business organization:

Sole proprietorship

Corporation

Partnership (omitted)

Family $(F)$ :

Son

$0.078 *$

0.028

$-4.543$

$-0.002$

No spouse

(2.194)

$-0.247$

$(-1.317)$

$-31.524 *$

$-0.025$

Spouse employed in

$(-22.006)$

$(-10.676)$

agricultural

$-0.426^{*}$

$-0.154$

$-29.023 *$

$-0.029$

Spouse nonagricultural

$(-14.904)$

$(-10.328)$

$-6.063^{*}$

$-0.015$

Other spouse (omitted)

(6.632)

$(-2.565)$

Exogenous income $(\boldsymbol{V})$ :

Spouse's incom

$-0.041 *$

$(-3.271)$

Investment income

$-0.020 *$

$(-6.956)$

$-0.131 *$

$(-24.181)$

Farm net income

$-0.036 *$

$(-5.870)$

Labor market conditions $(M)$ :

Population density

$-0.015^{*}$

$(-90.694)$

Male unemployment

$-0.353^{*}$

$(-84.289)$

\section{Region:}

British Columbia

$0.817^{*}$

(16.498)

Prairies

$0.210^{*}$

(7.413)

Ontario (omitted)

Quebec

$-0.636^{*}$

$(-15.501)$

Atlantic Canada

8.926*

(93.101)
$-0.015$

2.699*

(2.793)

$-0.103$

$(-0.345)$

$-0.080$

$(-0.7250$

$-3.493 *$

(-6.762)

$-0.006$

$0.069 *$

(4.914)

$-0.603$

$(-1.584)$

$-32.046^{*}$

(-7.810)

-33.548 *

$(-14.370)$

$-0.231$

3.236

$-35.930 *$

(-9.689)

$-26.522$

$(-3.204)$
0.014

$-0.035$

$-0.017$

$-0.095$

$-0.023$

0.009

$-0.0001$

$-0.00008$

$-0.136$

$-0.006$ 
Model statistics:

\begin{tabular}{lcr} 
Observations & 53,143 & 23,251 \\
Chi-square & 52,822 & \\
Correlation coefficient & 0.50 & $-137,080$ \\
Log likelihood & $-10,008$ & \\
Total percentage & & \\
correctly predicted & 95 & \\
\hline a $t$-statistics are in parentheses. & \\
* Significant at the 5\% level. &
\end{tabular}

labor supply. Dairy operations have the largest decrease in marginal probability of off-farm participation, followed by hog operations and "others." Both dairy and hogs are negative, but not significant in labor supply. Having a wheat farm has a positive effect on both off-farm participation and labor supply, but it is significant in only labor supply.

Type of business organization is the other farm characteristic included. Being a sole proprietorship has no significant effect on either labor participation or labor supply. Being incorporated has a significant negative effect on labor participation and a significant positive effect on labor supply.

Family characteristics, $F$, has mixed effects. Having a son working on the farm increases the probability of off-farm work, but decreases (not significantly) the number of hours worked. Not having a spouse is negative and significant in both equations, as is having a spouse who works in agriculture. However, a spouse working but not in agriculture has a significant and positive affect on off-farm participation and a negative and significant effect on the amount of labor supplied.

Exogenous income, $V$, also had mixed effects. Spouse's income is significant in both equations, but it is negative in off-farm participation and positive in labor supply. Other exogenous income has a negative and significant affect on off-farm participation. Government support payments are negative and significant in decreasing both off-farm participation and labor supplied.
Labor market conditions, $M$, have small, significant affects on labor participation and supply. Increased population density is negatively associated with off-farm participation but positive in labor supply. The male unemployment rate is negative in both equations, but significant only in off-farm participation.

Lastly, region of Canada has a significant effect on the parameter estimates in both equations. Compared with Ontario (the omitted region), all other regions except for Quebec have greater labor participation but a lower labor supply.

\section{DISCUSSION}

Using two separate equations to estimate offfarm labor participation and labor supply allows for mixed effects, and hence insights, that would not be possible from a singleequation model. Fourteen of the variables have different signs in the Probit and truncated regression equations. A single-equation model would have restricted these variables to one sign, limiting the explanatory power of the model.

An example of the insights gained through the two-equation approach is how human capital, $H$, as proxied by age, education, experience and wages, affected off-farm labor participation and labor supply. In the unreported single-equation Tobit model of labor supply, education is negative. However, in the two-equation model, more education decreases the likelihood of offfarm labor participation, but increases the 
hours worked for those who do work offfarm. A reasonable explanation of these opposite signs is that the marginal productivity of farm work likely increases with education, which increases the returns from farm work and decreases the need to supplement farm income with off-farm work. However, for those who do work off-farm, their higher education also increases their value off-farm in terms of higher wages and hence the number of hours worked. Note that human capital, in particular age and education, has the largest effect of all the variables in terms of marginal probabilities and elasticities on labor participation and labor supply, respectively.

Experience affects labor participation and supply differently, and is also different from age. Whereas participation decreases at a decreasing rate with age, participation has a U-shaped response to experience. Farmers with 0-9 years experience and more than 20 years of experience have a greater probability of working off-farm than do those farmers with 10-20 years of experience. It is possible that this U-shaped response is related to the standard growth curve of a business, in which more time and effort is required in the middle to high growth phase than in the early, start-up or later, mature phases of a business. Labor supply also has different responses to age and experience. Supply increases at a decreasing rate with age, but decreases with years of experience. Hence, age and experience should be not viewed as equivalent. A 60-year-old farmer with 20 years of farm experience will likely have a different off-farm labor supply from a 60year-old farmer with 40 years of farm experience.

Wages also have mixed signs in the two equations. It is expected that higher wages lead to greater likelihood of working offfarm, as indicated by the positive wage parameter in the participation equation and as has been reported in previous studies (Sumner 1982; Furtan et al 1985). Hence, the negative sign in the labor supply equation is unexpected. However, a backward-bending labor supply curve is consistent with the underly- ing theory and can be explained. It is reasonable that there is a threshold of total wages desired to supplement farm income. Beyond that threshold, farmers would rather spend more time on the farm or on leisure and less time working off-farm. Moreover, experience and education, which increase the offfarm wage, also increase the marginal value of labor on the farm, increasing the cost of foregone farm work. Hence, while higher wages increase the probability of off-farm participation, higher wages are also associated with a decreased labor supply for those farmers who do work off-farm.

Farm characteristics, $E$, have expected signs. Gross farm sales as a proxy for size are negative in both labor participation and labor supply, as expected. The larger the operation, the less likelihood of working off-farm. Regardless of the farmer's productivity on a per-unit basis (e.g., acres, head), the opportunity cost of time away from the farm is greater for the operator of a larger farm. In effect, the reservation wage of the large farm operator is higher than the reservation wage of a farm small operator.

Farm type also yields expected signs. The negative, significant sign for dairy operations has the third largest marginal probability in the labor participation equation. Only age and education have a larger effect on the probability of working off-farm. The relatively inelastic response in the labor supply equation is consistent with expectations: ceteris paribus, dairy farmers have a high marginal value of their labor on the farm and not a lot of flexibility with their time. Hogs and fruits and vegetables have similar signs and responses, only of a lesser magnitude. The signs on cattle and poultry are somewhat unexpected. The authors' bias is that both are part-time enterprises; hence, the negative signs for labor participation are unexpected. However, their signs for labor supply are positive but not significant. Regardless of sign and significance, the marginal impacts and elasticities indicate that having a cattle or poultry operation does not have a large impact on either labor participation or labor supply. A similar story can be told for wheat: 
it is positive in both equations, significant only in labor supply, but the marginal probability and elasticity are so small that ceteris paribus being a wheat farmer has little impact on labor participation or supply.

"Other" types of operations have negative, significant signs in both equations, but it is difficult to determine what, if anything, the estimates indicate. It could be that farmers of uncommon or nontraditional enterprises are less likely to work off-farm and, when they do, it is for fewer hours.

Type of business organization is expected to have a more significant impact. Partnership is omitted as the default. Sole proprietorships are expected to be mostly smaller farms, on which the farmers are more likely to work off-farm, while members of corporations are expected to have larger operations with less likelihood of work offfarm. The signs on corporation are as expected, but the negative and not significant parameter on sole proprietorship is unexpected. Given the relatively low income level at which the maximum Canadian marginal tax rate applies and given the tax savings realized through incorporation, type of business organization may not be important in estimating and determining behavior of farm operators. In the past, incorporation indicated a large, highly profitable farm. Today, given our tax structure, type of business organization may have little bearing on the relative size and profitability of a farm enterprise.

Family characteristics, $F$, appear to affect both labor participation and labor supply. Previous studies have reported that the farm operator and spouse's labor allocation decisions are jointly determined (Huffman and Lange 1989; Lass and Gempesaw 1992). Having a spouse, and the type of work the spouse does, has a much larger impact on labor participation than does having a son working on the farm. Moreover, having a spouse working, but in not in agriculture, has more than twice the effect on labor participation as having a son. Hence, having a spouse working outside agriculture may be indicative of a family receptive to opportunities off-farm, while having a spouse working in agriculture may indicate a family view of few options off-farm. However, in the labor supply equation, all the family characteristic variables are very inelastic, indicating that family structure may affect labor participation, but that it has a relatively small effect on labor supply.

Exogenous income, $V$, is expected be negative in both labor participation and labor supply. Hence, the positive, and significant, sign on spouse's income in labor supply is somewhat surprising and difficult to explain. The magnitudes of the marginal probabilities on labor participation should be noted. Both net farm income and spouse's income have a larger effect on labor participation than does government support. Hence, changes in farm income and the long-term trend of increased labor participation by farm wives can be expected to have a larger impact on off-farm work than changes in government programs.

Local labor market conditions, $M$, also have a smaller effect on the probability of working off-farm than expected. Both farm type and region have a larger affect on labor participation than local market conditions. Farmers in B.C., the prairies and Atlantic Canada are more likely to work off-farm than farmers in Ontario and Quebec, but for fewer hours. Hence, gearing rural employment programs to local unemployment rates may have less impact on a farmer's labor participation and labor supply decision than simply gearing those programs to region.

\section{SUMMARY}

This study models off-farm labor supply as separate off-farm labor participation and offfarm labor supply. This approach is preferred to a single-equation model of off-farm labor supply because several of the variables in the model affect participation and labor supply differently. Age, education and wages have large, significant effects on both the probability of off-farm labor participation and on the amount of off-farm labor supplied. However, increased age and education decrease the probability of labor participa- 
tion and increase labor supply, while increased wages have the opposite effects. These opposite effects of a variable on labor participation and labor supply would be lost in a single-equation approach.

The data used in this study are unique in that this is the first published study of offfarm labor supply using Statistics Canada's Agriculture-Population Linkage Database of census-farm operators. As such, it is a national study of farm operator labor allocation by farm type and region. Previous studies are either dated or have estimated offfarm labor supply for a particular region.

The evidence of a backward-bending labor supply curve is unexpected and contrary to findings of previous studies, but is consistent with the underlying theory. The strong positive response to wages in previous studies (e.g., Furtan et al 1985) is possibly due to using a small, regional data set or more likely because the single-equation approach confounds labor participation and labor supply into one response.

Perhaps the most significant factor is that government efforts to stabilize and supplement farm incomes through rural employment programs may have less effect on labor allocation decisions than do the underlying demographic factors of age, education and experience, the farm type and regional factors. Labor supply is much more elastic with respect to education than to government support or to local market conditions. Programs to increase education levels can be expected to have a greater impact on off-farm employment than programs geared to local market conditions such as the unemployment rate. Moreover, as the general education level rises along with the average age of Canadian farmers, the reservation wage of those farmers will increase also, further decreasing the impact of many rural employment programs.

\section{NOTES}

${ }^{1}$ Several Journal reviewers have questioned whether farm characteristics (e.g., size and type of operation) and family characteristics (e.g., presence of a son and/or a spouse and the spouse's type of work) should be considered exogenous to labor allocation decisions. The concern is that labor allocation decisions are jointly determined with farm and family characteristics. However, farm and family characteristics enter the model through the farm production function, in which they are considered exogenous fixed or quasifixed inputs. Moreover, Bollman (1979) demonstrated that it is theoretically consistent to model off-farm work and farm productivity as independent. A relationship between labor supply and farm and family characteristics is expected, but the direction of causality is indeterminate. It may be more reasonable to assume that farm and family characteristics affect short-run labor allocation decisions, as modeled in this paper, than that short-run labor allocation decisions affect longrun farm and family structure.

${ }^{2}$ A Journal reviewer correctly pointed out that a farm with only $\$ 250$ of sales in a year is likely a hobby farm and should not be considered a commercial enterprise; the results may be biased by including these small-scale farms. However, given that minimum sales of $\$ 250$ was Statistics Canada's definition of a farm in 1986, and that policies were made and programs designed based in part on information from this data, we decided to follow Statistics Canada's lead and include all official designated farms in our sample. Given this wide range of farm size as indicated by farm sales, homoscedasticity is tested and not rejected.

\section{ACKNOWLEDGMENT}

This research was funded in part by the Canadian Farm Business Management Council, Statistics Canada and the Ontario Ministry of Agriculture, Food and Rural Affairs. All errors and omissions are the responsibility of the authors.

\section{REFERENCES}

Bollman, R. 1973. Off-farm work by operators of Canadian census farms C 1971. Canadian Farm Economics 8 (6): 1-5.

Bollman, R. 1979. Off-farm work by farmers: An application of the kinked demand curve for labor. Canadian Journal of Agricultural Economics 27 (1): 37-60.

Furtan, W. H., G. C. Van Kooten and S. J. Thompson. 1985. The estimation of off-farm labor supply functions in Saskatchewan. Journal of Agricultural Economics 36: 211-20.

Gould, B. and W. Saupe. 1989. Off-farm labor market entry and exit. American Journal of Agricultural Economics 71: 960-69. 
Gunter, L. and K. McNamara. 1990. The impact of local labor market conditions on the offfarm earnings of farm operators. Southern Journal of Agricultural Economics 19 (3): 155-65.

Heckman, J. 1974. Shadow prices, market wages, and labor supply. Econometrica 42: 679-94.

Heckman, J. 1976. The common structure of statistical models of truncation, sample selection and limited dependent variables and a simple estimator for such models. Annals of Economic and Social Measurement 5: 475-92.

Heckman, J. 1979. Sample selection bias as a specification error. Econometrica 47: 153-61.

Huffman, W. 1980. Farm and off-farm work decisions: the role of human capital. Review of Economics and Statistics 62: 14-23.

Huffman, W. 1991. Agricultural household models: survey and critique. In Multiple Job-Holding Among Farm Families, edited by M. C. Hallberg, Jill Findeis and Daniel Lass. Ames, IA: Iowa State University Press.
Huffman, W. and M. D. Lange. 1989. Off-farm work decisions of husbands and wives: Joint decision making. Review of Economics and Statistics 71: 471-80.

Killingsworth, M. 1983. Labor Supply. New York: Cambridge University Press.

Lass, D. and C. M. Gempesaw II. 1992. The supply of off-farm labor: A random coefficient approach. American Journal of Agricultural Economics 74: 400-08.

Lin, T. F. and P. Schmidt. 1984. A test of the Tobit specification against an alternative suggested by Cragg. The Review of Economics and Statistics 62: 174-77.

Sumner, D. 1982. The off-farm labor supply of farmers. American Journal of Agricultural Economics 64: 499-509.

Swidinsky, M., W. Howard and A. Weersink. 1998. Off-Farm Work by Census-farm Operators: An Overview of Structure and Mobility Patterns. Statistics Canada Working Paper 38. Ottawa: 